ISSN 2236-0859

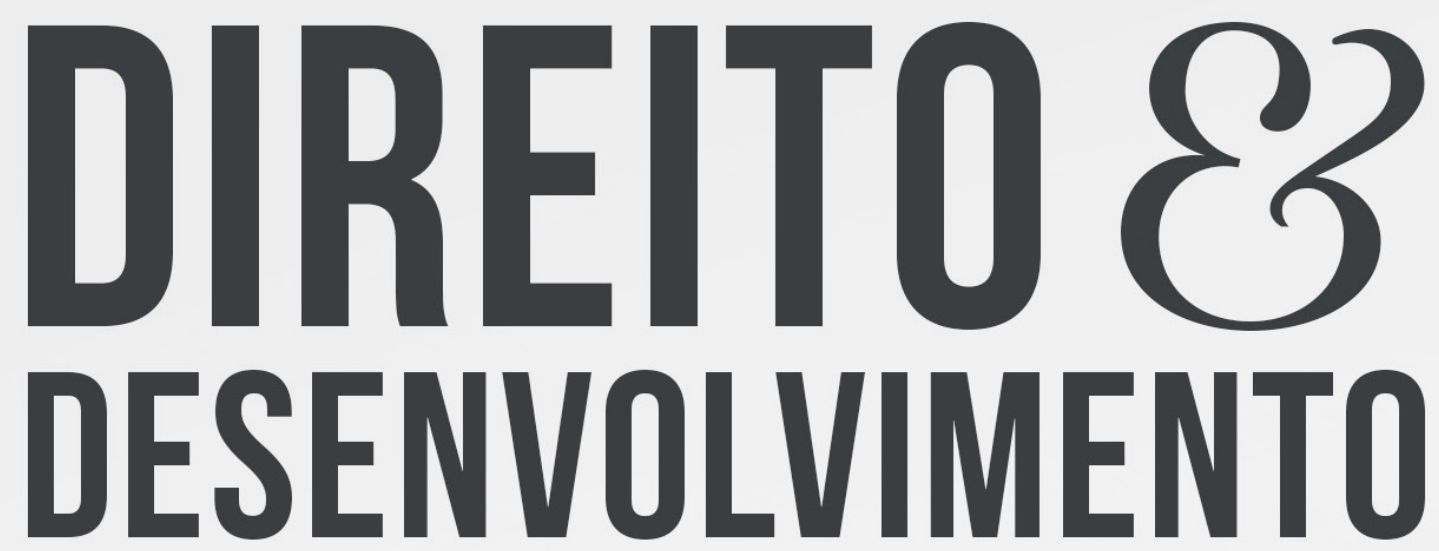

REVISTA DO PROGRAMA DE PÓS-GRADUAÇÃO EM DIREITO MESTRADO EM DIREITO E DESENVOLVIMENTO SUSTENTÁVEL

\title{
O ESTADO PLURINACIONAL EO SISTEMA PLURIJURIIICO: UM AVANÇO NO DESENVOLVIMENTO DA SOCIEDADE LATINOAMERICANA
}

JOSÉ ALBERTO ANTUNES DE MIRANDA MOISÉS NOÉ DE FRAGA 


\title{
O ESTADO PLURINACIONAL E O SISTEMA PLURIJURÍDICO: UM AVANÇO NO DESENVOLVIMENTO DA SOCIEDADE LATINOAMERICANA
}

\section{THE PLURINATIONAL STATE AND THE PLURIJURIDICAL SYSTEM: AN ADVANCE IN THE DEVELOPMENT OF LATIN AMERICAN SOCIETY}

Recebido: 02/05/2019

Aprovado: 10/06/2019
José Alberto Antunes de Miranda ${ }^{1}$ Moisés Noé de Fraga ${ }^{2}$

\section{RESUMO:}

O cenário constitucional latino-americano, demonstrou ao mundo europeu e norteamericano, a possibilidade de alcançar uma nova racionalidade social e política, especialmente no que se refere às decisões do Estado. A democracia do estado plurinacional vai além dos mecanismos representativos majoritários propiciando espaço crescente para os instrumentos institucionalizados de construção de consensos. O objetivo desse artigo é apresentar a evolução da visão de modernidade, destacada pela construção social do Estado, onde as constituições e os movimentos de mudança emergem em um cenário moderno na busca pela equiparação do diverso no cenário latino americano por meio do Estado plurinacional e do sistema plurijurídico. A metodologia utilizada é a fenomenológica, constatando os fatos para, a partir dos mesmos, tecer possibilidades explicativas com potencial de fornecer um quadro compreensivo da realidade que se tenta abranger. Conclui-se que existem muitas melhorias e avanços a serem alcançados, partindo de uma luta já iniciada pelo descolonialismo e intitulada como um avanço social democrático. Interesses políticos, em muitos momentos da história da América Latina, se sobrepuseram aos interesses coletivos, em especial a população indígena originária campesina, mas que devem ser superados para que o teor Pluralista tenha plenitude em sua intenção de abrangência coletiva.

Palavras-chave: Estado Plurinacional. Sistema Plurijurídico. Sociedade. América Latina.

\begin{abstract}
:
The Latin American constitutional scenario demonstrated to the European and American world the possibility of achieving a new social and political rationality, especially with regard to the decisions of the State. The democracy of the plurinational state goes beyond the majority representative mechanisms, providing an increasing space for the institutionalized instruments of consensus building. The purpose of this article is to present the evolution of the vision of modernity, highlighted by the social construction of the State, where the constitutions and

1 Doutor em Estudos Estratégicos Internacionais pela UFRGS, Mestre em Relações Internacionais pela Universidade Federal do Rio Grande do Sul, Assessor de Assuntos Interinstitucionais e Internacionais e professor permanente do Mestrado em Direito e Sociedade além de integrar o corpo docente do Curso de Relações Internacionais da Universidade La Salle. E-mail: jose.miranda@ unilasalle.edu.br

2 Mestre e Especialista em Direito pela Unilasalle/Canoas-RS; Doutorando em Direito e Ciências Sociais junto a UNC - Universidade Nacional de Córdoba/Argentina. Advogado. E-mail: moisesfraga@hotmail.com
\end{abstract}


the movements of change emerge in a modern setting in the search for the assimilation of the diverse in the Latin American scenario through the plurinational State and the plurijuridical system. The methodology used is the phenomenological one, stating the facts for, from the same, to weave explanatory possibilities with the potential to provide a comprehensive picture of the reality that is tried to cover. It is concluded that there are many improvements and advances to be achieved, starting from a struggle already initiated by the decolonialism and titled as a democratic social advance. Political interests, at many moments in the history of Latin America, have overlapped collective interests, especially the native peasant indigenous population, but must be overcome so that the Pluralist content has fullness in its intention of collectively.

Keywords: Plurinational State. Plurijuridical System. Society. Latin America.

\section{INTRODUÇÃO}

Por meio da evolução dos movimentos sociais, houve com o passar do tempo um reconhecimento constitucional dos direitos originários na América Latina. A busca por elementos de consolidação do princípio democrático de diálogo e de igualdade dos povos propuseram novos debates que se disseminaram na região.

Parte-se de $1492^{3}$, um período descrito como muito importante da modernidade, pois ocorreu um embate entre o europeu e seus não semelhantes. Neste momento temporal, aconteceu uma enorme discussão que culminou no pensamento moderno de supremacia política, social e cultural da Europa, comparada aos demais povos. (DUSSEL, 1995)

Numa visão eurocentrista, onde a Europa estava no centro do mundo, haveria um mundo diverso da África, Europa e Ásia. Ocorreria assim, um momento de descobrimento e conquista da América, quando as influências históricas passariam a ser cada vez mais relevantes. A Europa ganharia essa importância no mundo ao qual seria entendida como o único local possível de racionalidade humana, compondo seres perfeitos. Tal composição do ser europeu na modernidade compôs um mecanismo de imposição social, cultural e política, servindo também de alicerce no reconhecimento de tais direitos (SILVA, 2014).

Immanuel Maurice Wallerstein (2007, p. 73) cita o questionamento do europeu quando do encontro do povo persa, com uma inicial indagação de "como é possível ser persa?" e após imputando inferioridade do povo, por ausência de valores universais o que diverge do europeu.

Com o passar dos anos, o diferente foi sendo reconhecido como alguém que poderia pleitear a qualidade de igual ao europeu, tornando-se moderno. Neste diapasão, através do reconhecimento de direitos jurídicos e políticos aos diferentes, se enquadrariam como "cidadãos". Diante disso, percebe-se o cenário de um movimento denominado colonialismo, que decorre da formação de regiões que serviram aos anseios da política, economia e cultura de outros povos.

Tal reconhecimento daquilo que é fora dos padrões tornara-se um fato fundamental para o crescimento e a evolução de padrões, ultrapassando estigmas e preconceitos determinados para um biótipo social padrão até então aceito pela sociedade.

O objetivo desse artigo é apresentar a evolução da visão de modernidade, destacada pela construção social do Estado, onde as constituições e os movimentos de mudança emergem

\footnotetext{
3 Neste ano de 1492, ocorreu o descobrimento da América, assim como o período em que os Reis Católicos da Europa ocuparam a cidade de Granada, a qual era o último reduto muçulmano do continente europeu. Havia um biótipo europeu, o que era rechaçado caso não enquadrado nos padrões. Os diversos do padrão eram perseguidos, pois se buscava uma dominação cultural, pela força ou pela língua falada e escrita, eis que também era utilizada como instrumento de imposição (SILVA, 2014)
} 
em um cenário moderno na busca pela equiparação do diverso no cenário latino americano por meio do Estado plurinacional e do sistema plurijurídico.

Através desta imposição de novos paradigmas, houve muita destruição da cultura, pois havia um sentimento de dependência e de posse aos colonizadores ${ }^{4}$. Inclusive a prática da escravidão, já ultrapassada aos processos de socialização, deu lugar à regra, a modernidade, passando esta a desenhar estereótipo do ser moderno (SILVA, 2014).

Assim, o apogeu deste problemático processo de dominação ocorreu quando os colonizadores verificaram a necessidade de utilizar os povos originários da América como mero instrumento de exploração de suas propriedades, tido como um fato determinante para a construção do início da Modernidade (DUSSEL, 2012).

Diante desta situação, o processo de modernização, interferiu e possui reflexos na formação social da América Latina, que ainda hoje é considerada como um local de intensos conflitos étnico-culturais, havendo a criação de uma sociedade composta e híbrida. Deveria ser uma visão de início da hegemonização da cultura europeia sobre as outras, tendo como ponto de partida o sistema capitalista como precursor do mercado.

Essa grande diferenciação de estilos étnico-culturais, todavia composta por diferentes raças, origens e, consequentemente, culturas, demonstra uma mudança de um padrão, mas que ainda está em processo de desenvolvimento, visto que não é fixa ou imóvel.

\section{ORIGENS E CARACTERÍSTICAS DO ESTADO PLURINACIONAL}

A transição de um Estado que passa por uma transformação de ideal, qual seja, não mais seria um instrumento que não se pauta somente pela defesa da vida e da propriedade, mas também buscando conquistar a anuência do cidadão, através da luta por direitos universais. Houve uma busca por uma união de diferenças, produzindo o surgimento de um direito uniformizador, como elemento de nacionalização da população, integralizado na formação do Estado moderno, diante de um desenvolvimento político, social, cultural e econômico europeu (SILVA, 2014).

Boaventura de Sousa Santos destaca que houve também uma uniformização do conhecimento que passou a ser nacionalizado. Diante desta sistemática, somente seria válido se decorrente da cultura europeia, considerada a verdade. Os demais conhecimentos, não descritos como europeus eram desconsiderados por não integrarem um contexto científico da época (SANTOS, 2007).

Para José Luiz Quadros de Magalhães (2012) há um identificador da modernidade em relação ao surgimento e desenvolvimento do Estado, que objetiva a homogeneização, que culminará no processo de formação das hegemonias políticas, econômicas, sociais e culturais, negando a diversidade.

É importante destacar que na América Latina o processo de democratização ocorreu através de muitas lutas, em especial a mobilização operária, que surge durante o século XIX, demonstrando que o constitucionalismo moderno não se origina de valores democráticos.

Esta situação ensejou com que os burgueses, detentores do poder político do Estado, pudessem construir uma ordem jurídica que lhes garantisse liberdade para garantir a expansão dos negócios do capital, assim como uma ordem política que afirmasse a continuidade no poder, mediante voto censitário. Durante este período, o direito ao voto seria exercido pelas pessoas que cumprissem requisitos constitucionais como sendo: branco, europeu, cristão, média de 30 anos e um patrimônio considerável (SILVA, 2014).

4 Este estereótipo do ser moderno proporia um padrão que, se fosse diverso do racional na visão do europeu, contemplaria serem inexistentes, conforme descrito por Santos (2007). 
Eric Hobsbawm entende que esse nacionalismo moderno proporcionou a criação de um sentimento do ser nacional, assim como elementos contra hegemônicos, sendo que o liberalismo europeu forçou uma escolha dos ditos submissos para aceitarem o sistema ou seriam inferiorizados (HOBSBAWM, 1997).

As revoluções operárias daquela época transformaram esse modelo de Estado liberal, visando concretizar pensamentos das revoluções nacionais dos séculos passados. $\mathrm{O}$ objetivo desse constitucionalismo, não mais liberal de cunho social, era fortificar as classes mais fragilizadas da sociedade, diante de um novo paradigma político e econômico da época. Porém, tais movimentos não conseguiram introduzir o diverso para toda uma sociedade, mas somente a determinadas pessoas, pois o nacionalismo social abarcou ampla gama da população, por não condizer com o padrão da época.

Nesta imposição de constitucionalismo moderno frente à realidade latino-americana, após os movimentos de independência das antigas colônias, pode-se destacar que vigora a afirmação da continuidade do colonialismo mesmo após a independência, fortalecendo a presença das influências europeias.

Antonio Wolkmer salienta que as circunstâncias políticas para a criação do Estado, no contexto da América Latina, possuem intensa discussão sobre as diretrizes do processo de unificação política, jurídica e cultural, observado o ocorrido na Europa e nos Estados Unidos, eis que o Estado surge na América Latina antes da formação de estruturas sociais, o qual é o principal responsável por criá-las e separá-las dentro da sociedade (WOLKMER, 2001).

Já para Martin Van Creveld o processo de colonização se consistiu basicamente de indivíduos recém-chegados da Espanha ou de Portugal, como é o caso do Brasil, os quais monopolizavam os cargos mais importantes da sociedade, em diversos níveis. Tal construção que formou o Estado nacional, seja em relação aos colonizadores europeus, ou latinoamericanos, serviu a um processo que conduziu a uma civilização da modernidade, tendo como objetivo a satisfação das vontades de determinada parcela social dominante (CREVELD, 2004).

Esta passagem de um antigo para um novo modelo de Estado conduz a uma discussão da necessidade de formar um novo modelo de pacto social, político e econômico. Diante dessa necessidade, houve a construção tanto do modelo plurinacional quanto do constitucionalismo da diversidade na América latina, demonstrando que tal crise sistêmica possui um condão cultural.

O cenário constitucional latino-americano, demonstrou ao mundo europeu e norteamericano, a possibilidade de alcançar uma nova racionalidade social e política, especialmente no que se refere às decisões do Estado.

José Ribas Vieira destaca que uma das primeiras características das Constituições latinoamericanas é a inauguração de um constitucionalismo a partir de uma racionalidade indígena e campesina, compondo uma nova forma de Estado, direito e sociedade. Também descreve como característica deste novo constitucionalismo o povo ser visto como uma sociedade aberta de sujeitos constituintes, sobrepondo noções de identidade nacional, compostas na ceara de cultura hegemônica (VIEIRA, 2012).

Haveria três ciclos desse modelo plural: 
Quadro 1 - Ciclos do Modelo Plural:

\begin{tabular}{|l|l|}
\hline Primeiro Ciclo & $\begin{array}{l}\text { modelo plural que tem origem em um constitucionalismo multicultural (1982/1988), } \\
\text { frente às primeiras discussões sobre a insuficiência do modelo antigo em garantir } \\
\text { direitos }\end{array}$ \\
\hline Segundo Ciclo & $\begin{array}{l}\text { ascensão do constitucionalismo pluricultural (1988/2005), bus surgiu como } \\
\text { instrumento de reconhecimento da existência de uma sociedade multiétnicas e } \\
\text { de Estados Pluriculturais, citando como exemplo a Constituição Pluricultural da } \\
\text { Venezuela em 1999 }\end{array}$ \\
\hline Terceiro Ciclo & $\begin{array}{l}\text { surgimento do constitucionalismo plurinacional surgido em 20o6 no contexto da } \\
\text { Declaração das Nações Unidas sobre direitos indígenas, bem como os contextos das } \\
\text { assembleias nacionais constituintes da Bolívia e do Equador como precursores. }\end{array}$ \\
\hline
\end{tabular}

Fonte: Elaborado pelo autor, observado descrição de BALDI, 2015.

A partir da identificação desses ciclos se observa que o constitucionalismo latinoamericano busca um resgate do valor da constituição na promoção de uma sociedade mais justa, demonstrando a ampliação da participação popular na tomada das decisões pelo Estado a partir das recentes constituições latino-americanas.

A construção constitucional latino-americano, de plano, preocupa-se com a fundamentação e a legitimação da Constituição do Estado, sendo que posteriormente, buscar-se-á verificar a efetividade dessas Constituições. Esse movimento constituinte latino-americano, demonstra que as novas Constituições, citando especialmente da Bolívia, Equador, Colômbia e Venezuela, integram um novo contexto de direitos constituições que foge do paradigma geracional eurocêntrico, sendo base de discussões indígenas, campesinos, definindo estes como sujeitos de direitos em um novo cenário político de decisões sociais e econômicas do Estado.

Augustín Grijalva destaca que o constitucionalismo plurinacional seria o novo tipo de constitucionalismo pautado por relações interculturais igualitárias que reinterpretam os direitos constitucionais e reestruturam a institucionalidade do Estado Nacional, propondo ainda um reconhecimento plural e deliberação intercultural democrática (GRIJALVA, 2008).

Através do novo constitucionalismo latino-americano ocorre uma maior e mais ativa participação da sociedade nas decisões de seu governo. Há uma busca por instrumentos de descolonização, através de um governo plurinacional que se instala, o qual transmite uma sensação de construção da democracia pela valorização da minoria. Entretanto, muitas destas aptidões de dever/conter do instrumento democrático de participação popular, discorre em um campo em que não há unanimidade, posto que nem todas as suas propostas são efetivas no sentido de resposta democrática.

Augustín Grijalva ainda refere que é fundamental ser comunicativo, concretizante e garantista. O novo modelo constitucional, decorrente de uma multiplicidade de ordenamentos jurídicos, deve ter um reconhecimento multicultural (GRIJALVA, 2008).

Este novo modelo constitucional visa recuperar a origem revolucionária das discussões constitucionalistas, reconstruindo percepções a contar da busca pela emancipação social daqueles que foram excluídos pela modernidade.

O novo constitucionalismo latino-americano plurinacional se baseia na tentativa de ruptura com o paradigma atual de Estado5 ${ }^{5}$ através de uma visão europeia, por ocasião da

5 Wolkmer e Fagundes propõe este novo paradigma atual de Estado, através de uma ruptura das dicotomias coloniais, que se norteava pela "dominação interna” e pela "submissão externa”. A adesão de modelos com matrizes eurocêntricas e norte-americanas, proporcionam estruturas de dominação econômica e de exclusão social. Inovações no campo geopolítico de lutas sociais, políticas e históricas, ocorre um avanço para o novo Constitucionalismo pluralista intercultural e pela refundação do Estado na América Latina. (WOLKMER, FAGUNDES, 2013) 
discussão de uma unidade normativa de uma Constituição, não necessariamente, representará uma uniformização social, política e cultural ao retorno de um modus vivendi hegemônico.

O constitucionalismo de matriz moderna, europeia, liberal, formatado pela figura do Estado nacional, não é mais integralmente satisfatório, especialmente em um contexto de diversidade étnico-cultural como é a América Latina (SANTOS, 2010).

A Constituição não pode ser visualizada como disciplina e limitações ao poder institucionalizado, eis que de fato também se trata de uma busca pela composição dos fundamentos de uma dada organização social, política, econômica e cultural, de modo a garantir tantos direitos conquistados ao longo dos anos (SILVA, 2014).

Frene a um cenário constitucional atual na América Latina que atrai para si olhares do mundo para as novas formações constitucionais dos Estados plurinacionais latino-americanos, podem ser vistos como um mecanismo de desencobrimento daqueles que foram vitimados pela modernidade europeia. Em todos os debates sobre esse constitucionalismo pluricultural, deve haver o reconhecimento do poder de dizer o direito, de uma pluralidade de conhecimentos que também merecem substrato do Estado, devendo haver o reconhecimento da importância da diferença.

O grande norte do pluralismo jurídico latino-americano, descrito especialmente pelas Constituições da Venezuela de 1999, do Equador de 2008 e da Bolívia em 2009 é a definição de centros de decisão comunitária, possibilitando outras formas de Direito estatal, eis que descrevem a legitimação de novos sujeitos sociais, coletivos, inclusive de juridicidade.

Segundo a CIPCA (2009) a jurisdição oficial e a indígena originária não podem e não são incompatíveis, mas sim se complementam de forma mútua, respondendo pela sua realidade social e cultural, tendo em vista a pluralidade de nacionalidades inseridas no contexto boliviano pós-reforma constitucional.

Em 2012 ocorreu um debate sobre competência ${ }^{6}$ entre a Justiça oficial e a indígena originária, podendo ensejar um grande conflito entre poderes regularmente constituídos. Ocorre que diante de entendimento do Tribunal Constitucional Plurinacional, houve decisão se utilizando de critérios culturais e antropológicos e tendo como base de estudos a Unidade de Descolonização do Tribunal Constitucional Plurinacional. Solucionado o embate em análise, fixou-se a coexistência de bases jurídicas diversas, observada a origem indígena e ordinária, sem qualquer enlace hierárquico ou de subordinação, fortalecendo o respeito entre as jurisdições.

Provocado, o Tribunal Constitucional Plurinacional da Bolívia analisou desde 20090 montante de 453 processos, sendo que a partir de 2010 houve um crescimento gradativo e muito significativo, atingindo o seu ápice em 2015 com 127 demandas. Neste ano de 2017, até 21 de agosto, já foram analisados 24 processos, o que deverá ser maior até o final do ano. Todavia, as demandas acima referidas, não refletem o total de ações discutidas e ajuizadas no âmbito da Bolívia neste período, mas somente aquelas que derivam de uma discussão constitucional e que sobem de instância para discussão.

O que se verifica é uma crescente busca por remédios jurídicos diversos aos manejados na instância inicial, seja por complexidade, seja por competência ou até a rediscussão da matéria de fato, o que possibilita entender que há ainda uma dificuldade no acesso ou na busca por Justiça.

A democracia do estado plurinacional vai além dos mecanismos representativos majoritários propiciando espaço crescente para os instrumentos institucionalizados de construção de consensos. Tal proposta de uma democracia consensual é compreendida no paradigma do estado plurinacional, sendo importante compreender que esta democracia

6 TRIBUNAL CONSTITUCIONAL PLURINACIONAL. Sentença Constitucional Plurinacional 1422/2012, de 24 de setembro de 2012. Disponível em: < http://buscador.tcpbolivia.bo/_buscador/(S(4mkjglgnqgirwnbjbensp34w))/WfrJurisprudenciar.aspx>. Acesso em: 14 out. 2017. 
inicia a partir de uma mudança de postura para o diálogo, não existindo consensos prévios, especialmente consensos linguísticos, construídos na modernidade de forma hegemônica e autoritária.

José Luiz Quadros Magalhães (2012) destaca que:

\begin{abstract}
O estado moderno homogeneizou a linguagem, os valores, o direito, por meio de imposição do vitorioso militarmente. A linguagem é, neste estado moderno, um instrumento de dominação. Poucos se apoderam da língua, da gramática e dos sentidos que são utilizados como instrumento de subordinação e exclusão. O idioma pertence a todos nós e não a um grupo no poder. A linguagem, é claro, contém todas as formas de violência geradas pelas estruturas sociais e econômicas. Logo, o diálogo a ser construído por esses meios hegemônicos. Tudo deve ser discutido levando-se em consideração a necessidade de descolonização dos espaços, linguagens, símbolos e relações sociais, pessoais e econômicas. O diálogo precisa ser construído a partir de posições não hegemônicas, e isto não é só um discurso, mas uma postura.
\end{abstract}

Unificar a linguagem foi um mecanismo do estado moderno, coadunando-se com um pensamento de soberania, mas, sobretudo elenca a linguagem como um instrumento poderoso, que pode refletir um estado de ser e uma atitude a ser tomada em busca de uma descolonização.

Inúmeros questionamentos podem surgir, eis que fazem embate a um pensamento ainda colonialista, propondo ausência de resposta às problemáticas em sede de uma nova jurisdição, porém, Boaventura dos Santos salienta que essa jurisdição indígena a ser aplicável, exclusivamente aos povos indígenas e dentro dos territórios indígenas (SANTOS, 2007).

Em que pese um problema a ser solucionado, não pode desconstruir o novo paradigma constitucional da América Latina atual, seja pelo fato das situações de rompimento, seja pela jurisdição monista da modernidade em substituição ao pluralismo medieval. Já as expressões na Constituição da Bolívia de 2009 remetem a uma mudança, não só no teor, mas também na forma, pois expressa, nos direitos e garantias fundamentais do indivíduo ou da coletividade, reconhecendo como "remédios constitucionais", afastando expressões em latim como "habeas corpus" ou "habeas data".

Para Silva esse seria o pluralismo epistemológico na luta pela formação de uma nova identidade social, presente e necessária para a construção multicultural de uma nova racionalidade para os Direitos Humanos, privando pela diversidade do outro, a partir de elementos criados por este novo modelo de Estado Plurinacional (SILVA, 2014).

A busca por uma discussão bilateral, fugindo de uma realidade eurocentrista para algo diverso do padrão. Com o passar dos tempos houve uma constatação: o diverso pode ser moderno e igualitário. É natural uma mudança nos parâmetros padronizados por inúmeros fatores, pois a modernidade tem o intuito de construir modelos de Estados diversos ao convencional. Ocorre uma transição entre os direitos de defesa da vida e da propriedade, passando para uma luta por direitos universais. São fusões e transições de diferenças necessárias ao crescimento de uma nação.

A obediência a ciclos de evolução do constitucionalismo latino-americano denota um resgate do valor da constituição na busca por uma sociedade mais justa, possibilitando a participação da população em todas as etapas sociais. Propor mudanças é matéria complexa, eis que ocorre o enfrentamento do capitalismo global colonizador e de uma formação de sociedade historicamente sustentada na Europa.

A Bolívia possui sua importância, pois traz subsídios para um questionamento sobre a evolução dos movimentos sociais como agente ativo de uma nova matriz social, desta feita, regulamentada na Constituição com garantias e direitos de igualdade entre povos originários 
indígenas ou não, se auto-regulamentando e auto-administrando, seja no campo social e também jurídico. Nesta esteira, o Estado Plurinacional será disciplinado a seguir, tendo como viés de compartilhamento a democracia, que em consonância ao novo paradigma contemporâneo, compõe uma nova figura social em destaque na América Latina.

\section{O ESTADO PLURINACIONAL E A DEMOCRACIA NO CONTEXTO LATINO AMERICANO}

Democracia possui uma expressão de participação popular nas decisões, propondo um regime político que viesse do povo, seja ela de forma direta ou indireta.

Para Norberto Bobbio, a democracia pode ser classificada como aquela que ocorreu na Grécia Antiga, onde haviam audiências públicas com a participação de todos. Também descreve a "democracia do moderno", qual seja, de forma indireta, quando as decisões são tomadas por representantes populares (BOBBIO, 1986).

Também há uma divisão de Norberto Bobbio para a democracia, a qual pode localizarse em três grandes tradições do pensamento jurídico:

a) teoria clássica seria aquela em que a democracia seria como Governo de todos os cidadãos e diversa da monarquia;

b) teoria medieval que remete a uma hierarquia de sobreposição ancestral, transmitindo em uma vocação ascendente para descendente;

c) teoria moderna, conhecida também como teoria de Maquiavel, quando as formas de Governo seriam duas: monarquia e a república, tendo a antiga democracia como uma forma de república, onde se origina expressão democrática e republicana, popularmente denominada ao invés de democracia, de república.

Optar pela autonomia, pela escolha é o cerne da democracia, sendo necessária a política para sua estruturação que, por sua vez, tende a uma separação de classes e interesses.

A democracia não pode se restringir a uma discussão social em um determinado momento, figurando esta nova perspectiva latino-americana de constitucionalismo (LINERA, 2010).

A democracia implica em mudança e transformação, as quais não são formadas por maiorias, mas sim por todos, não havendo necessidade de mecanismos contra-majoritários, eis que não há mais a vitória da maioria como fator de decisão.

Daniela Cademartori e Sérgio Cademartori apontam uma visão kelseniana de direito, destacando o Estado de direito composto por um cenário de poder coercitivo, que está sempre em constante regulação e limitação. Tal designação utilizada nos Estados de Direito, seria o meio mais eficaz para a solução de conflitos sociais, o que se torna um dos grandes problemas da convivência em sociedade (CADEMARTORI, CADEMARTORI, 2006).

Para os autores, o garantismo modifica o conceito de democracia, pois denomina de democracia substancial ou social o Estado de direito composto por garantias determinadas, sejam elas liberais ou sociais. Já a democracia formal ou política tem o setor político como regulamento da fonte de sua normatividade, assim referindo: "a democracia formal refere-se ao Estado político representativo, que tem no princípio da maioria a fonte da legalidade, a democracia substancial ou social nada mais é do que o Estado de direito dotado de garantias efetivas, tanto liberais quanto sociais" (CADEMARTORI, CADEMARTORI 2006, p. 160).

Elizabeth do Nascimento Mateus assinala que o Estado Plurinacional proporciona uma alternativa de enfrentamento dos efeitos do capitalismo neoliberal com embate ao povo 
boliviano. Seria necessária uma recomposição do Estado na busca pela superação das crises. Muito embora a população boliviana integre uma demarcação de classes sociais fragmentadas no decorrer dos anos, fundamental a descrição da sua rotatividade democrática e participativa (MATEUS, 2011).

Diante desta visão, poderia estar se privilegiando discursos majoritários, interpretados muitas vezes como expressões equivocadas do povo, desconsiderando grupos minoritários, cuja voz é cerceada por ocasião do lançamento dos anseios que não são ouvidos no plano político, eis que ocorre a falta de impulsão emanada pela vontade do todo. A estrutura da democracia se consolida quando a maioria da população apoia e incentiva a escolha de representantes enquanto regime político, atuando na defesa dos direitos humanos fundamentais (SQUEFF, 2016).

Neste aspecto a forma organizada e política das nações indígenas pode contribuir para a reorganização e recomposição do Estado boliviano, sob o escopo democrático, envolvendo diversos povos, através de um Estado democrático, organizando-se em um processo coletivo, participativo e dialógico (MATEUS, 2011).

Para Gabriel Barbosa de Oliveira Filho o Estado boliviano no âmbito da América Latina nasceu de uma forma elitista imaginando uma nação estruturada na exclusão da maioria de sua população por critérios raciais. Porém, movimentos questionadores de base e algumas lideranças compuseram um campo político, buscando uma expansão da nação boliviana compondo todo o povo e democratizando o seu Estado (OLIVEIRA FILHO, 2012).

Faz-se necessário um instrumento de decisão que se impõe ao final do debate de formação de um consenso quanto aos interesses sociais, efetivada no interior de uma democracia participativa, primando pelo interesse da maioria. A democracia participativa tem um teor discriminatório no que se refere às práticas a serem definidas pelos políticos eleitos pela população. Diante da positivação de direitos indígenas e o reconhecimento da multiculturalidade pelo voto majoritário. Afinal, quem pode realizá-los são os próprios indígenas nos limites de suas diferenças culturais e em consonância com as suas tradições (SQUEFF, 2016).

José Luiz Quadros de Magalhães destaca que a ideia de Estado Plurinacional pode superar as bases uniformizadoras e intolerantes do Estado nacional, em que todos os grupos sociais devem se conformar aos valores determinados na constituição nacional em termos de direito de família, direito de propriedade e sistema econômico entre outros aspectos importantes da vida social (MAGALHÃES, 2012).

Essa crise política existente no Estado Democrático de Direito, que merece ser debatida sob o aspecto da diversidade, do multiculturalismo, da inclusão do outro no Estado, deve contemplar um verdadeiro pluralismo político-jurídico, visando quebrar a corrente homogeneizadora das maiorias, contemplada sobre o Estado Moderno.

Oliveira Filho também salienta que o Estado Plurinacional seria uma nacionalização do sujeito indígena, como sendo um dos principais elementos da condição de um Estado Plurinacional em construção, reconhecendo o risco de um sujeito idealizado em sua função histórica. A autonomia da comunidade é um elemento principal do horizonte indígenacomunitário, pois é onde ocorre uma legitimação de deliberações comunitárias, momento em que os povos indígenas podem escolher suas autoridades e representantes segundo seus usos e costumes (OLIVEIRA FILHO, 2016).

Observamos que houve uma evolução na América Latina da necessidade de haver a reescrita da democracia, em uma perspectiva multiétnica, ensejando a existência de vários argumentos válidos, dependendo da origem dos indivíduos, que refletem uma pluralidade de influências. Um Estado Pluriétnico impõe modificações institucionais e estruturais do Estado, 
em diversos setores, objetivando considerar todos os elementos plurais de cada setor, devendo ser considerado as regras comunitárias legítimas para a resolução dos conflitos

O cenário latino-americano ainda é cheio de situações de dominação interna e de submissão externa. O pensamento colonialista, que se origina da exclusão dos entes plurais. Aderimos a modelos de cultura oriundos da Europa e Estados Unidos. A luta pela implantação dos parâmetros eurocêntricos para os países latinos demonstra os novos movimentos político-jurídicos, propiciando modificações no Estado (Plurinacional) e também no Direito (Pluralismo Jurídico).

Conforme Henrique Weil Afonso e José Quadros de Magalhães, com o desenvolvimento do Estado Plurinacional surgem novas possibilidades de lidar com tais diferenças culturais. A plurinacionalidade seria uma certeza da incompetência de cada cultura, pregando por um debate aberto, inclusivo e fomentado pelo reconhecimento. O debate plurinacional contempla uma superação de dicotomias excludentes, que originaram a intenção civilizatória das nações desenvolvidas (AFONSO e MAGALHÃES, 2011).

A busca por modificar instituições e organizar uma nova sociedade plural na América Latina é uma situação difícil, pois também remonta a necessidade de desconstruir outras instituições que inviabilizam o desenvolvimento do Estado Plurinacional nesse continente. Haveria ainda grandes questões sobre as relações de poder que sucumbiriam para riscos de uma nova hegemonia no Estado, contrário ao Plurinacional. A globalização acabou por também fomentar o modelo uniformizador do Estado, desprezando a soberania destes e indiferente com as fronteiras culturais, baseado no argumento da supranacionalidade.

\section{O EXEMPLO DA BOLÍVIA COMO ESTADO PLURINACIONAL NO ÂMBITO DA SOCIEDADE LATINO AMERICANA}

Luiz Tapia descreve de forma pontualizada a questão do Estado Plurinacional para a busca da recomposição do estado na Bolívia. O grande fator negativo, segundo Tapia seriam as nações comunitárias, as quais possuem uma matriz social, em que tudo se organiza em torno da forma comunitária. Na Bolívia, haveria inclusive inúmeros grupos aymara e quéchua que vivem nas cidades ou até fora do país, o que traz consigo uma característica forte de não conter uma forma estatal, pois conduziriam sua visão e posição baseado em sua cultural, desprezando uma orientação ou influências de um Estado colonial preponderante até então (TAPIA, 2007).

Haveria uma dificuldade destas culturas se adaptarem a uma formação social, quando a política tem influência e que necessite de representantes que venham a administrar os bens comuns e de também tomar decisões, legislar, dentre tantas outras situações diversas de uma cultura originária.

Luis Tapia destaca que a cultura aymara não experimentou, nem em período préhispânicos, a concentração política de uma forma estatal, destacando que "no hay un modelo político del estado aymara que pueda servir de substituto o como una parte de un nuevo Estado plurinacional.7”. Em contrapartida, o povo quéchua possui uma identidade cultural, em especial a questão linguística, eis que possibilita a substituição de língua, costumes e práticas políticas, mas mantém a matriz cultural de organização socioeconômica (TAPIA, 2007).

Ocorre ainda a possibilidade da busca ou reivindicação de ser uma nação dentro de outra nação, refletindo em grandes conflitos, o que é ocasionado pela diversidade e pela situação enfrentada ao compor um Estado Plurinacional. ${ }^{8}$

7 TAPIA, Luiz. Uma reflexión sobre la idea de Estado plurinacional em OSAL. Buenos Aires: CLACSO. Año VIII, n. 22, septiembre de 2007. Disponível em: < http://biblioteca.clacso.edu.ar/ar/libros/osal/osal22/D22Tapia.pdf>. Acesso em: 14 out. 2017 , OSAL 53. 8 A busca pelo reconhecimento de nações dentro de nação aymara e quechua, fomentam grandes conflitos através dos séculos em diversos lugares do País, em especial a região norte de Potosí. (TAPIA, 2007). 
A equiparação da Constituição Boliviana entre a justiça tradicional indígena e a justiça ordinária do país, dispõe que cada comunidade indígena pode propor seu tribunal, com julgadores eleitos entre os moradores, cujas decisões são irrecorríveis na justiça comum, não havendo uma hierarquia entre ordenamentos jurídicos comuns e indígenas (SQUEFF, 2016).

Para Iorran Aquino e Monalisa Pinheiro, o processo de formação e desenvolvimento das nações está em aberto, continua sendo exercido pelos povos latinos, fugindo de uma imagem europeia. No modelo boliviano houve uma expectativa de superação do velho Estado capitalista e colonial para um modelo societal, predispondo uma diversidade étnica. Inverterse-ia a lógica de gerência estatal anterior a plurinacionalidade apresentar-se-ia como uma espinha dorsal do propósito e fim da ação governamental (AQUINO, PINHEIRO, 2013).

Ao analisar as discussões judiciais interpostas junto ao Tribunal Constitucional Plurinacional da Bolívia, pode-se verificar o volume de demandas que chegam ao Tribunal, que tratam sobre o povo indígena e seus conflitos. Observa-se uma ruptura das regras padronizadas, possibilitando a superação dos ditames normais, abrangendo elementos diversos como família, propriedade, economia, sociedade, etc., primando por um debate coletivo e democrático por elos da sociedade desconectados dos padrões hierárquicos diversos. ${ }^{9}$

A forma democrática plurinacional decorre de uma consequência positiva dos povos indígenas, antes marginalizados pela sociedade, mas que passam a integrar a concretização de suas lutas. Com o passar dos tempos, verifica-se que o Estado necessita transformações, visando, essencialmente uma maior participação.

Já para as mudanças com o surgimento do Estado Plurinacional é uma modificação necessária para ocorrer o reconhecimento dos direitos contra-majoritários, afirmando a diversidade de costumes, tradições, linguagens, integrante de um pensamento colonialista de dominação (SQUEFF, 2016).

A partir destas mudanças impostas pela efetivação do Estado Plurinacional, ocorre uma revolução no sentido do Estado se desprender das bases teóricas e sociais de um estado nacional constitucional e democraticamente representativo, características adotadas por muitos Estados latino americanos como modelo ideal.

Este Estado Pluriétnico proporciona uma nova estrutura aos entes estatais, modificando relações sociais até então presentes, primando um novo tipo de integração, respeitando a diferença e o fim da homogeneização da população (SQUEFF, 2016).

A Constituição da Bolívia se caracteriza por buscar atender as demandas históricas do povo indígena e maximizar a capacidade de conflito com que maneja o Estado, evoluindo de uma repressão aos choques étnicos e culturais, buscando trazer o reconhecimento das diferenças e propondo poder a estas. Há a busca por um Estado refundado e coordenado pelas maiorias sociais, que busca uma solução para a desburocratização que impera nos Estadosnações, elevando a busca por um novo-Estado e por um novo modelo de sociedade primada por programas democráticos e populares (AQUINO; PINHEIRO, 2013).

A afirmação principal do Estado Plurinacional de Direito integra o reconhecimento que denota o povo indígena de decisão para suas primazias, anseios e propriedades (SQUEFF, 2016).

A identificação e o respeito pelo teor democrático coletivo, imposto pelo Estado Plurinacional, remete também a instituição de um sistema jurídico diferenciado e de cunho plural, descrito como plurijurídico sendo uma proposta de coalisão aos anseios do coletivo.

9 Fonte: Pesquisa do autor junto ao Sistema de Informação Constitucional Plurinacional. Disponível em: <http://buscador.tcpbolivia. bo/_buscador/(S(4mkjglgnqgırwnbjbensp34w))/WfrJurisprudenciaı.aspx>. Acesso em: 14 out. 2017. 


\section{O SISTEMA PLURIJURÍDICO NO CONTEXTO DO ESTADO PLURINACIONAL: PERSPECTIVAS}

O protagonismo indígena foi fundamental para provocar a redefinição do modelo de Estado-Nação, abrindo frente para um "constitucionalismo latino-americano" e a incorporação do pluralismo jurídico.

Houve assim uma onda de constitucionalização de direitos e liberdades fundamentais orientadas por uma leitura moral do Direito, voltada para o reconhecimento do outro, propondo a diversidade e a pluralidade de culturas no discurso do multiculturalismo, que abriu espaço para o reconhecimento das identidades étnicas.

A Constituição da Bolívia, em uma linha Plurinacional possui uma característica muito importante ao contemplar cerca de 80 dos 411 artigos que tratem sobre a questão indígena, conforme descrito no texto constitucional ${ }^{10}$.

Verifica-se que há concessão aos povos indígenas de auto-regulamentação, bem como independência de seus próprios "tribunais", não tendo uma dupla jurisdição ou revisão por instância superior, propondo uma forma constitucional em nível local. Pode-se citar o Art. $179^{11}$ da Constituição do Estado Plurinacional da Bolívia, que trata sobre o organograma judicial da Bolívia, assim como os artigos $190^{12}$ e $191^{13}$. Já o artigo $192^{14}$ descreve a força das decisões de jurisdição indígena, pois no inciso I demonstra que todos devem acatar as decisões da jurisdição indígena originária campesina.

A Constituição prevê a criação de um Tribunal Constitucional Plurinacional, composto por integrantes eleitos pelo sistema ordinário e também pelo sistema indígena ${ }^{15}$. Diante da nova proposta de organização territorial do país há uma previsão de uma divisão em quatro níveis de autonomia: a) departamental (correspondente aos Estados Brasileiros); b) regional; c) municipal; d) indígena.

Diante desta proposta, cada uma das regiões autônomas pode promover eleições diretas de seus governantes e administrar seus próprios recursos, de forma independente. Ocorrem

\footnotetext{
10 os 36 "povos originários" (aqueles que viviam na Bolívia antes da invasão dos europeus), passam a ter participação ampla efetiva em todos os níveis do poder estatal e na economia. Com a aprovação da nova Constituição, a Bolívia passou a ter uma cota para parlamentares oriundos dos povos indígenas, que também passarão a ter propriedade exclusiva sobre os recursos florestais e direitos sobre a terra e os recursos hídricos de suas comunidades. A Constituição estabelece a equivalência entre a justiça tradicional indígena e a justiça ordinária do país. Cada comunidade indígena poderá ter seu próprio "tribunal", com juízes eleitos entre os moradores. As decisões destes tribunais não poderão ser revisadas pela Justiça comum. (MAGALHÃES, 2009).

11 Artículo 179. I. La función judicial es única. La jurisdicción ordinaria se ejerce por el Tribunal Supremo de Justicia, los tribunales departamentales de justicia, los tribunales de sentencia y los jueces; la jurisdicción agroambiental por el tribunal y jueces agroambientales; la jurisdicción indígena originaria campesina se ejerce por sus propias autoridades; existirán jurisdicciones especializadas reguladas por l ale.

12 Artículo 190. I. Las naciones y pueblos indígena originario campesinos ejercerán sus funciones jurisdiccionales y de competencia a través de sus autoridades, y aplicarán sus principios, valores culturales, normas y procedimientos propios.

II. La jurisdicción indígena originaria campesina respeta el derecho a la vida, el derecho a la defensa y demás derechos y garantías establecidos en la presente Constitución.

13 Artículo 191. I. la jurisdicción indígena originario campesina se fundamenta en un vínculo particular de las personas que son miembros de la respectiva nación o Pueblo indígena originario campesino. II. La jurisdicción indígena originario campesina se ejerce en los siguientes ámbitos de vigencia personal, material y territorial: 1. Están sujetos a esta jurisdicción los miembros de la nación o Pueblo indígena originario campesino, sea que actúen como actores o demandado, denunciantes o querellantes, denunciados o imputados, recurrentes o recurridos. 2. Esta jurisdicción conoce los asuntos indígenas originario campesinos de conformidad a lo establecido en una Ley de Deslinde Jurisdiccional. 3. Esta jurisdicción se aplica a las relaciones y hechos jurídicos que se realizan o cuyos efectos se producen dentro de la jurisdicción de un Pueblo indígena originario campesino.

14 Artículo 192. I. Toda autoridad pública o persona acatará las decisiones de la jurisdicción indígena originaria campesina. II. Para el cumplimiento de las decisiones de la jurisdicción indígena originario campesino, sus autoridades podrán solicitar el apoyo de los órganos competentes del Estado. III. El Estado promoverá y fortalecerá la justicia indígena originaria campesina. La Ley de Deslinde Jurisdiccional, determinará los mecanismos de coordinación y cooperación entre la jurisdicción indígena originaria campesina con la jurisdicción ordinaria la jurisdicción agroambiental y todas las jurisdicciones constitucionalmente reconocidas.

15 CONSTITUCIÓN POLÍTICA DEL ESTADO (CPE) Bolivia, 7 febrero 2009. Artículo 197. I. El Tribunal Constitucional Plurinacional estará integrado por Magistradas y Magistrados elegidos con criterios de plurinacionalidad, con representación del sistema ordinario y del sistema indígena originario campesino.
} 
também mudanças de ordem religiosa, pois passa da religião oficial católica para um Estado Laico (MAGALHÃES, 2009).

Para Elisabeth do Nascimento Mateus, existe uma constitucionalização da diversidade étnica, tendo como ponto de partida a valorização e o reconhecimento da estruturação da cultura, costumes e tradições indígenas, elencando e respeitando direitos de propriedade e propondo uma efetividade jurídica ao alcance dos povos (MATEUS, 2011).

Haveria a necessidade de um núcleo jurídico da diversidade étnica e cultural que é multidimensional, delimitando o campo normativo da diversidade étnica, dentre vários núcleos jurídicos.

Na dimensão jurídica, é conferido aos indígenas autonomia para tomar decisões sobre questões relacionadas ao processo de territorialização abrangendo, inclusive, a autodemarcação dos limites territoriais necessários à sua reprodução física e cultural.

Para tanto, pode-se destacar a importância constitucional de tais parâmetros segundo Elisabeth do Nascimento Mateus (2013):

(...) os parâmetros de interpretação constitucional devem coincidir com a perspectiva internacional, ao declarar que os povos indígenas têm direito a livre determinação segundo a qual determinam livremente sua condição política e buscam livremente o seu desenvolvimento econômico, social e cultural, consistindo o direito de todos os povos de buscar o seu desenvolvimento material, cultural e espiritual enquanto grupo social, ou seja, de controlar seu próprio destino.

Através de uma nova realidade enfrentada entre a população indígena envolvida neste novo paradigma jurídico de Estado Plurinacional, surgem dúvidas e questionamentos quanto à realidade fática enfrentada por estes novos sujeitos, sendo possível questionar o seu teor ou não de justiça.

Em face destes questionamentos, serão explicitados elementos que possam impor, ratificar ou rechaçar a importância ou a depreciação da expressão “justiça” para fins de julgados dos povos indígenas, já no contexto plurijurídico, dentro de um Estado Plurinacional.

\section{CONCLUSÃO}

As modificações trazidas pela globalização originaram a inclusão e a exclusão de direitos sociais e políticos. Os movimentos sociais, por meio de novos mecanismos de participação, tiveram um importante papel na reivindicação por transformações. A globalização também ocasionou a incidência de fatores negativos como a velocidade da força econômica, refletindo no peso da moeda, assim como a preponderância de uma classe capitalista transnacional como as multinacionais que criam desigualdades a nível mundial.

O movimento globalizante levou a necessidade de ampliar o teor democrático e participativo da população, de delinear mecanismos de regramento, imponto limites na organização social, o que seria uma forma de sugestionar soluções de desigualdade no campo social. A intenção de ampliar a participação popular demonstra o fortalecimento de um processo de transformação social.

$\mathrm{O}$ respeito pelos direitos sociais se denotam amplo e complexo, fortalecendo os direitos igualitários, além do respeito aos princípios fundamentais ao trabalho e à saúde. Estas transformações desenvolveram o mercado de capitais, evoluindo o Produto Interno Bruto da Bolívia e alterando indicadores de pobreza no País.

A importância de um novo modelo de Estado remete ao pensamento de uma forma mais participativa, elevando o olhar da sociedade atual para o debate das minorias, dispondo de 
uma auto-organização das massas historicamente colonizadas, o que demonstra a importância sobre o debate.

A trajetória de luta da população originária propiciou a amplitude do sentimento indígena, culminando em um dispositivo constitucional que alinhavou todo o ordenamento jurídico para o surgimento de um novo paradigma na América Latina. Reformas constitucionais foram necessárias, mas muitas possuíam interesse eleitoral, pois traziam em seu interior a ampliação de mandatos a seus governantes. Questionamentos políticos foram levados a esteira do conhecimento da população, seja antes, durante ou depois da promulgação da Constituição do Estado Plurinacional, os quais foram sobrepostos por um sentimento de valorização do povo.

A construção das primeiras Constituições latino-americanas possui uma importância e um teor indígena e campesino, compondo uma nova forma de Estado, de direito e de sociedade. Nesta esteira da construção, dividem-se as intenções políticas e sociais em três ciclos, iniciando em 1982, passando por transformações e busca de reconhecimento multiétnico e de romper o paradigma atual do Estado.

Assim, na luta por reconhecimento de um múltiplo de atores e coletivos, o pluralismo jurídico latino-americano, teve sua importância legitimada, principalmente, pela formação de novos sujeitos sociais, fortalecendo em muito o ressurgimento dos movimentos sociais, já que os conflitos atuais se tornaram complexos.

Apesar de tais mudanças ocorrerem também no meio econômico, seu principal teor democrático plural tomou destaque ao propor igualdade de direitos e culturas, suprimindo o colonialismo e a discriminação na região latino americana. A promoção da configuração do Estado plurinacional e de um sistema plurijurídico se firmou a partir de características próprias.

Existem muitas melhorias e avanços a serem alcançados, partindo de uma luta já iniciada pelo descolonialismo e intitulada como um avanço social democrático. Interesses políticos, em muitos momentos da história da América Latina, se sobrepuseram aos interesses coletivos, em especial a população indígena originária campesina, mas que devem ser superados para que o teor Pluralista tenha plenitude em sua intenção de abrangência coletiva.

O Estado plurinacional e o sistema plurijurídico promoveram um enorme avanço na América Latina como instrumento democrático de fortalecimento do cidadão, servindo de referência a novos estudos sobre o tema, a fim de auxiliar outros países e distintas culturas neste processo de descolonização.

\section{REFERÊNCIAS}

AFONSO, Henrique Weil; MAGALHÃES, José Luiz Quadros de. Revista Brasileira de Direito Constitucional - RBDC n. 17 - jan./jun. 2011. O Estado Plurinacional da Bolívia e do Equador: matrizes para uma releitura do direito internacional moderno. Disponível em: <http://www. esdc.com.br/RBDC/RBDC-17/RBDC-17-263-Artigo_Henrique_Weil_Afonso_e_Jose_Luiz_ Quadros_de_Magalhaes_(O_Estado_Plurinacional_da_Bolivia_e_do_Equador).pdf $>$. Acesso em: jul. 2017.

AQUINO, Iorran; PINHEIRO, Monalisa. O Estado Plurinacional como saída para a crise do Estado Moderno: a Contribuição Indígena às formas de Estado-nação. 2013. Disponível em: <https://semanaecopol.files.wordpress.com/2013/10/gt-1-iorran-dias-aquino-o-estadoplurinacional-como-saczadda-para-a-crise.pdf $>$. Acesso em: jul. 2017. 
BALDI, César Augusto (Coord.). Aprender desde o Sul: Novas constitucionalidades, pluralismo jurídico e plurinacionalidade. Aprendendo desde o Sul. Belo Horizonte: Fórum, 2015.

BOBBIO, Norberto. O futuro da Democracia: uma defesa das regras do jogo. Marco Aurélio Nogueira (Trad.) Rio de Janeiro: Paz e Terra, 1986.

CADEMARTORI, Daniela Mesquita Leutchuk de; CADEMARTORI, Sergio. A relação entre Estado de direito e democracia no pensamento de Bobbio e Ferrajoli. Revista Sequência, n. 53, p. 145-162, dez. 2006.

CIPCA - Centro de Investigación y Promoción del Campesinado. Jurisdição Indígena Originária Campesina. 15 abr. 2009. Disponível em: < http://www.cipca.org.bo/index.php/cipca-notas/ zdpa/348--sp-2097312965>. Acesso em: 14 out. 2017.

CONSTITUCIÓN POLÍTICA DEL ESTADO (CPE) Bolívia, 7 febrero 2009. Disponível em: \&lt; https://www.oas.org/dil/esp/Constitucion_Bolivia.pdf\&gt;. Acesso em: 14 out. 2017.

CREVELD, Martin Van. Ascensão e Declínio do Estado. Tradução de Jussara Simões. São Paulo: Martins Fontes, 2004.

DUSSEL, E. The Invention of the Americas: Eclipse of "the Other" and the Myth of Modernity, Continuum Intl Pub Group, 1995

GRIJALVA, Augustín. El Estado Plurinacional e Intercultural en La Constitución Ecuatoriana del 2008. In: Ecuador Debate 75. Quito-Ecuador, dez. 2008. p. 49-62. Disponível em: <http:// www.ecuadordebate.com/wp-content/uploads/2010/o6/Ecuador-debate-75.pdf >. Acesso em: 10 jun. 2017.

HOBSBAWM, Eric J. A Era do Capital: 1848-1875. Tradução de Luciano Costa Neto. 5. Ed. São Paulo: Paz e Terra, 1997.

LINERA, Álvaro Garcia, A potência plebeia: ação coletiva e identidades, operárias e populares na Bolívia, 2010. Trad. Mouzar Benedito e Igor Ojeda. São Paulo: Boitempo, 2010.

MAGALHÃES, José Luiz Quadros de. Direito à Diversidade e o Estado Plurinacional. Belo Horizonte: Arraes Editores, 2012.

MAGALHÃES, José Luiz Quadros de. Estado Plurinacional na América Latina. 27 mar. 2009. Conteúdo Jurídico. Disponível em: < http://www.conteudojuridico.com. $\mathrm{br} /$ ?colunas\&colunista=50\&ver=257>. Acesso em: 1 nov. 2016.

MATEUS, Elizabeth do Nascimento. Considerações sobre o Estado Plurinacional Boliviano. In: Âmbito Jurídico, Rio Grande, XIV, n. 89, jun 2011. Disponível em: <http://www.ambitojuridico.com.br/site/?n_link=revista_artigos_leitura\&artigo_id=9625\&revista_caderno=16>. Acesso em: 15 jun. 2017. 
OLIVEIRA FILHO, Gabriel Barbosa Gomes de. Constitucionalismo Boliviano e Estado Plurinacional: solução de conflitos e autogoverno nas autoridades indígenas originárias campesinas. Rio de Janeiro: Jumen Juris, 2016.

SANTOS, Boaventura de Sousa. Para Além do Pensamento Abissal: das linhas globais a uma ecologia dos saberes. Revista Crítica de Ciências Sociais, no 78, p. 3-46, out. 2007.

Refundación del Estado en América Latina. Instituto Internacional de Derecho y Sociedad, Lima. Julho 2010.

SILVA, Heleno Florindo da. Teoria do Estado Plurinacional: o novo constitucionalismo latinoamericano e os direitos humanos. Curitiba: Juruá, 2014.

SQUEFF, Tatiana de Almeida Freitas Rodrigues Cardoso. Estado Plurinacional: a proteção do indígena em torno da construção da hidrelétrica de Belo Monte. Curitiba: Juruá, 2016.

TAPIA, L. Consideraciones sobre el estado plurinacional. In: BALDI, César augusto (Coord.). Aprender desde o Sul: Novas constitucionalidades, pluralismo jurídico e plurinacionalidade. Belo Horizonte: Fórum, 2015.

TAPIA, L. Uma reflexión sobre la idea de Estado plurinacional em OSAL. Buenos Aires: CLACSO. Año VIII, n. 22, septiembre de 2007. Disponível em: < http://biblioteca.clacso.edu. ar/ar/libros/osal/osal22/D22Tapia.pdf>. Acesso em: 14 out. 2017.

VIEIRA,JoséRibas.RefundaroEstado:onovoconstitucionalismolatino-americano.Universidade Federal do Rio de Janeiro. Disponível em: < https://pt.scribd.com/document/24243799/UFRJNovo-Constitucionalismo-Latino-Americano>. Acesso em: 10 jun. 2012.

VIEIRA, Oscar Vilhena. Desigualdad estructural y Estado de derecho. In: GARAVITO, César Rodríguez (Coord.). El derecho em América Latina: un mapa para el pensamiento jurídico del siglo XXI. Buenos Aires: Siglo Veintiuno Editores, 2011.

WALLERSTEINS, Immanuel Maurice. Pluralismo Jurídico, Direitos Humanos e Interculturalidade. Revista Sequência, n. 43, p. 113-128, dez. 2007.

Pluralismo Jurídico: fundamentos de uma nova cultural no direito. São Paulo: AlfaÔmega, 2001.

. FAGUNDES, Lucas Machado. Para um novo paradigma de Estado Plurinacional na América Latina. Revista NEJ - Eletrônica, Vol. 18 - n. 2 - p. 329-342 / mai-ago 2013. Disponível em: <www.univali.br/periodicos>. Acesso em: 10 jun. 2013. 